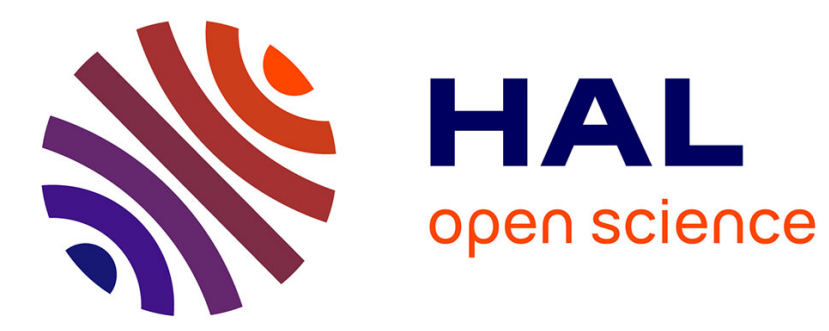

\title{
Digitization and Preservation of Cultural Heritage Products
}

\author{
Abdelhak Belhi, Sebti Foufou, Abdelaziz Bouras, Abdul H. Sadka
}

\section{To cite this version:}

Abdelhak Belhi, Sebti Foufou, Abdelaziz Bouras, Abdul H. Sadka. Digitization and Preservation of Cultural Heritage Products. 14th IFIP International Conference on Product Lifecycle Management (PLM 2017), Jul 2017, Seville, Spain. pp.241-253, 10.1007/978-3-319-72905-3_22 . hal-01764208

\section{HAL Id: hal-01764208 \\ https://hal.inria.fr/hal-01764208}

Submitted on 11 Apr 2018

HAL is a multi-disciplinary open access archive for the deposit and dissemination of scientific research documents, whether they are published or not. The documents may come from teaching and research institutions in France or abroad, or from public or private research centers.
L'archive ouverte pluridisciplinaire HAL, est destinée au dépôt et à la diffusion de documents scientifiques de niveau recherche, publiés ou non, émanant des établissements d'enseignement et de recherche français ou étrangers, des laboratoires publics ou privés.

\section{(c)(1)}

Distributed under a Creative Commons Attribution| 4.0 International License 


\title{
Digitization and Preservation of Cultural Heritage Products
}

\author{
Abdelhak Belhi ${ }^{1,2,(\bowtie)}$, Sebti Foufou ${ }^{3,4}$, Abdelaziz Bouras ${ }^{1}$, Abdul H. Sadka \\ ${ }^{1}$ CSE, Qatar University, Doha Qatar \\ \{abdelhak.belhi, abdelaziz.bouras\}@qu.edu.qa \\ 2 DISP Laboratory, University Lumière Lyon 2, Lyon, France \\ ${ }^{3}$ Lab. Le2i, Université de Bourgogne, Dijon, France. \\ sfoufoudu-bourgogne.fr \\ ${ }^{4}$ New York University Abu Dhabi, Abu Dhabi, UAE. \\ sfoufoulnyu. edu \\ ${ }^{5}$ Brunel University, London, United Kingdom \\ abdul.sadka@brunel.ac.uk
}

\begin{abstract}
.
Cultural heritage encompasses various aspects of a nation's history. Cultural heritage artifacts are considered as priceless items that need special care. Since the wide adoption of new digital technologies, documenting and storing cultural heritage assets became more affordable and reliable. These records are then used in several applications. Researchers saw the opportunity to use digital heritage recordings for long-term preservation. They are considering cultural heritage artifacts as products, and the history behind them as a product lifecycle. In this paper, we present the research progress in cultural heritage digital processing and preservation, highlighting the most impactful advances. Additionally, we present the CEPROQHA project which is a new approach aiming at achieving cost-effective acquisition and digital preservation for cultural heritage artifacts in Qatar.
\end{abstract}

Keywords: Cultural heritage, PLM, 3D Modeling, Semantic enrichment, Digital preservation, CEPROQHA project.

\section{Introduction}

Cultural heritage $(\mathrm{CH})$ digitization and preservation are two complex processes that involve several underlying techniques and algorithms to make $\mathrm{CH}$ mockups available for current and future generations. Digital content preservation is inspired from the manufacturing industry where companies use adapted archival platforms and PLM frameworks to store critical data and knowledge about important facts at each stage of product lifecycle. This data can be very important in the future for several reasons such as avoiding previous mistakes or for iterative purposes.

In this paper, we consider cultural heritage assets as products, their history as a lifecycle, and study their lifecycle preservation from a product viewpoint. In order to express

adfa, p. 1, 2011.

(c) Springer-Verlag Berlin Heidelberg 2011 
the need behind the long term-preservation of cultural heritage several concepts need to be introduced. In the following, we present three major concepts: Digital heritage where we describe the impact of digital imaging technologies on $\mathrm{CH}$, Digital obsolescence where we highlight the dangers of data extinction, and finally we introduce Longterm digital preservation which is the current solution for data extinction.

\section{Digital Heritage}

All nations around the world give a high value to their culture and traditions. The longterm preservation of the national moral identity is the concern of every nation. Cultural heritage assets are priceless items with a very high historical value. Maintaining and conserving these assets is a top priority for all communities.

Since the emergence of digital technologies, museums and $\mathrm{CH}$ reconstruction and conservation organizations are considering adapting these technologies for cultural heritage digitization. Museums are digitizing their collections not only for cultural heritage preservation, but also for making their collections accessible for a larger audience in an attractive way, like using Virtual Reality (VR), Augmented Reality (AR), 3D TV, etc. These technologies are integrated into web based platforms adapted to cultural content consumption.

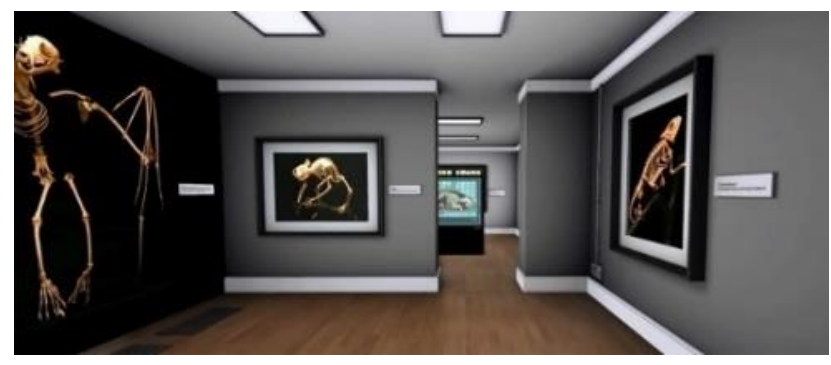

Fig. 1. Virtual Museums Tours

This new form of exhibition opened a new era for cultural heritage. Recent studies showed that only $10 \%$ of the global cultural heritage assets are exhibited in museums [1]. The other $90 \%$ are deposited in museums archives because of their non-importance compared to other more attractive artifacts, or simply because of their heavy physical degradation. Digital solutions like virtual museums can overcome these issues using tools like 3D model digital curation. In fact, the digital copy of a $\mathrm{CH}$ asset can be curated making its restoration cost-effective and more reliable. It can also be linked to a digital collection and valued with semantic enrichment by linking it to other attractive artifacts or simply highlighting its history.

\section{Digital Obsolescence}

Nowadays, with the wide adoption of information technology, every organization has to adapt its resources to be part of the digital era. However, with the high evolution pace of technology, the fear from digital obsolescence became more important than the 
fear from physical data loss. Digital obsolescence, or data extinction, is the state where the archived data becomes no more readable or usable. This obsolescence has two major reasons: the first one is the hardware obsolescence: the media storing the data is obsolete (for example the 5.25" and 3.5" floppy disks) or physically degraded. The second reason, which is the most important, is software obsolescence. This type of obsolescence can have several reasons, mainly the loss of the required knowledge to interpret the data, like what can happen for early CAD formats like GEM or IBM CAD [2]. To overcome these issues, several researchers are focusing on how to preserve the data for long-term archival [3-5]. This research ranges from data formats, best practices, to standards and frameworks.

\section{Long-term Digital Preservation}

Digital preservation is a common process in the manufacturing industry $[3,6]$. Recently, digital preservation became primordial in many sectors like: the medical field, historical and cultural fields, e-commerce, e-government, etc. From another side, the increasing performance of processing systems and the dropping costs of archival media are encouraging knowledge based organizations to consider digital preservation.

Digital preservation is not a generic process that can be applied directly in every context. In fact, the needs for the preservation of data for a car parts manufacturing company are different from those of a pharmaceutical company.

The majority of digital preservation approaches relies on the OAIS RM (Open Archival Information System Reference Model) [7]. OAIS is a conceptual reference model intended for the management, archival and long-term preservation of digital documents. It is considered as milestone achievement in long-term digital preservation.

OAIS describes the processes, the duties of each actor, and the overall architecture for a sustainable long-term digital archiving system. These characteristics guarantee and ensure the long-term availability of the archived data, and protect it from all kind of hazards (mainly digital obsolescence).

The rest of this document is organized as follows: In section two, we present a survey of cultural heritage digitization techniques, enrichment, content management and preservation. This is followed in section three by a brief description of some projects related to cultural heritage preservation. In section four, we present CEPROQHA which is a new research project aiming for cost-effective $3 \mathrm{D}$ acquisition and digital preservation for cultural heritage artifacts.

\section{Related Work}

Digital preservation for cultural heritage is widely studied. Several research projects are funded all over the world to establish, not only standards and good practices, but also some novel ideas in order to adapt existing approaches from other fields to the field of cultural heritage. Data about cultural heritage is stored in several file formats. Digital preservation is about the standards and best practices that guide the acquisition and the 
conservation steps. In this section, we discuss the impact of 3D technologies on cultural heritage, and present a survey of current innovations related to long-term digital heritage acquisition, enrichment, content management and digital preservation.

\subsection{D digital heritage acquisition and modeling}

The massive advances in 3D imaging had a positive impact on digital heritage. Some researchers are comparing this impact to the one of photography in the $19^{\text {th }}$ century [8]. $3 \mathrm{D}$ acquisition for cultural heritage assets is very critical, since assets are very fragile and their handling requires special care. The scanning of cultural heritage assets is very complicated compared to normal objects. In fact, $\mathrm{CH}$ assets often require restricted access and cannot be easily manipulated (touching, moving, rotating, etc.), which further complicates their scanning process [9]. Nowadays, with the advances in imaging capture and processing technologies, high quality captures can be performed using handheld devices. Software like: SELVA3D [10], Smoothie 3D [11] or AutoDesk 123D [12] can transform a 2D still image to a digital 3D model. These programs take as input different images, taken from several viewpoints, and generate a 3D model as shown in Fig. 2.

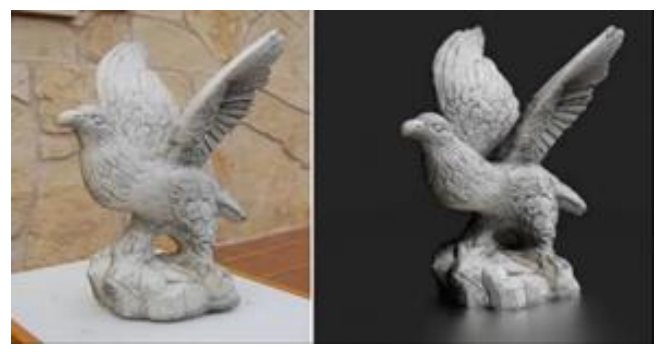

Fig. 2. Original item (Left) and its 3D model (Right)

For large objects, solutions involving a moving video camera, like SLAM technologies [13] or the Google Tango project [14], are often considered. These technologies can be used to capture large surface areas and monuments cost-effectively using computer tablets and smartphones.

In the cultural heritage sector, 3D modelling is still based on conventional techniques. For large size sites, commercial tools like AgiSoft Photoscan [15], AutoDesk 123D [12], Pix4D [16], Arc3D Web service [17] or even Potomodeler [18] are used. These tools are cost-effective as they can use images captured by average consumer devices like smartphones or tablets cameras. However, they suffer drawbacks such as time efficiency, and the lack of instantaneous feedback because of the separation between the acquisition and the modelling steps. In fact, the user doesn't get an instantaneous feedback. So, and in case the modelling fails, the user must take additional shots and the whole modelling process needs to be repeated. Recently, some high-end techniques were proposed. For instance, the CultLab3D [19] is a high-end 3D scanning system for cultural heritage assets digitization. However, this system is very expensive and cannot 
handle all types of assets (size limitation). Besides, this system is not portable as it consists of a large 3D scanner (see Fig. 3.).

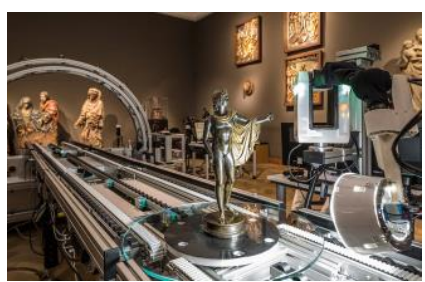

Fig. 3. CultLab3D Professional Scanner

Given the limitations of the aforementioned approach, in our work, we need a new 3D scanning framework, which must be able to scan all types of assets, with no size limitation. More importantly, it must be cost-effective, portable and give instantaneous 3D models.

Many academic research has been undertaken in the field of 3D modelling of $\mathrm{CH}$ assets. These researches were pioneered by the Digital Michelangelo Project [20]. Some of these researches were also undertaken by the Visual computing lab of ISTI-CNR [8]. Generally, researchers focus on the use of several techniques like: laser triangulation, Photogrammetry, Structured light, time of flight, Stereo vision, and others [21,22]. For example, a new Photogrammetry and minimal image network adapted to the cultural heritage context is proposed in [23]. Other researchers are combining industrial techniques like Arc3D [17] and MeshLab [24]. Unfortunately, all these systems are very complex, lack cost-effectiveness and time efficiency. In addition, the majority of these systems are limited to specific use cases, as they are not designed with a user-centric approach.

3D Holoscopic imaging is an advanced true 3D imaging system. This technology enables full 3D immersion without special headgear [25-27], and offers the simplest form of recording and playing back a true $3 \mathrm{D}$ scene.

\subsection{Data Enrichment}

Data enrichment is the practice of enhancing, refining, valuing and linking the raw data. Semantic enrichment for cultural data has been an active and fruitful field of research in previous years. In 3D cultural heritage context, linking the collected data is a critical mission for many reasons. This process is tedious and requires a lot of analysis. 3D annotations are used to semantically enrich shapes, adding more knowledge to the 3D model. These annotations are associations between selected portions of the 3D shape and some data describing it.

The metadata schemes for cultural data are defined by several standards like the CIDOC-CRM or the CRMdig ontologies [28]. These standards aim at sharing cultural heritage information by a common and stretchable semantic scheme.

Several approaches tackled the semantic enrichment challenge of 3D models like AIM@SHAPE [29], 3D-COFORM [30], Focus K3D [31], CULTURA [32], V-MusT [33], and [34]. Some are using interactive annotations, some others are studying how 
to include more information in 3D model files (like X3D, VRML or others) [35], while other approaches are focusing on machine learning techniques to automatically generate these annotations [36].

\subsection{Content Management}

Museums around the world use special software applications to manage their $\mathrm{CH}$ inventory e.g. Software like MuseumSoftware [37], Adlib [38] and Museumplus [34]. These tools are data management systems used for cataloguing purposes. They list some data about assets illustrated by $2 \mathrm{D}$ images.

Some novel approaches were introduced too. 3D-COFORM, for example, used a secured repository infrastructure to store and manage 3D cultural data. We can also cite other frameworks like [39] where the authors presented a centralized content management system (CMS) adapted to cultural heritage with advanced functionality like semantic queries and distributed storage.

However, since new digital technologies emergence and the progress in 3D imaging, the application of 3D visualisation technologies has become very reliable and cost-effective, especially in the content consuming market with technologies like 3D television, Virtual Reality (VR) and Augmented Reality (AR). Nowadays, virtual museum software products like Versoteq [40] or 3DStellwerk [41] are used to create virtual museum tours adapted to variety of content consuming platforms (VR Headset, 3D TV, Smartphones and tablets, Etc.). 3D cultural heritage content is very attractive for consumers and considered as very lucrative. Several other software like SketchFab [42], which is a web-based 3D visualisation framework, focus on the 3D presentation of cultural heritage models.

The Fedora based 3D repository presented in [43] is a good example of a complete 3D digital heritage CMS. It has two core parts. The first part is a digital objects repository storing, aggregating, managing and extracting digital objects in a wide range of formats and data types. The second core component is a semantic resource index which establishes an indexing data structure for a complex information mapping for relations between an object and its components. This data structure is basically an ontology.

\subsection{Digital Preservation}

Due to the wide use of digital technologies to capture and store cultural heritage, the need to preserve this data for the future is becoming very important, especially because of the high value of the assets. Digital preservation is becoming more reliable than physical preservation, thanks to the increasing performance of processing systems and the dropping costs of archival media.

Digital Obsolescence is an alarming threat to every knowledge management organisation. These organisations fear the loss and the non-usability of their critical data in the future, especially that new technologies are being widely adopted [44].

Digital preservation is currently studied as a solution for digital obsolescence. The initial approach to digital preservation was the OAIS system (Open Archival Information System) in the mid 90's. This model established a platform and a definition of initial best practices and concepts of digital preservation [6,7]. From this milestone, several research projects focused on digital preservation, like ERPANET which studied digital 
knowledge exchange, LOTAR which aimed at establishing long term preservation standards for digital data like 3D CAD models, and PDM (Product Data Management) [45]. For 3D content preservation, MIT FAÇADE [46], DEDICATE [47], and DuraArk [48] studied standards and techniques to archive and preserve 3D architectural data for long term use.

The $3 \mathrm{D}$ data topic is very challenging when it comes to digital preservation. A 3D model by itself is not very descriptive. It needs to be enriched with semantic annotations and metadata. The first problem with this metadata is about how to define it and where to store it. In fact, if the data is separated from the 3D model file, it can be easily lost [43]. Besides, if the archiving operator omits some important features of the digitized asset, this error can be fatal in the future.

The first requirement is very clear. The overall output must be usable for future processing (future-proof). The main problem with 3D models is the interoperability. For example, some proprietary (closed) file formats are becoming obsolete because of restrictions to their use (closed source and ad-hoc structure) [43]. The inability to use custom software to process this data is a major drawback. These issues led to the creation of new 3D file formats like X3D, VRML and COLLADA, which are widely used nowadays. From another side, several metadata standardisation approaches exist. The most impactful one is the CIDOC-CRM, which is an ontology describing the relationships and the concepts used in the context of cultural documentation $[28,43]$.

\section{Progress and efforts for Cultural Heritage preservation}

In this Section, we present the overall goals and the approaches used within several research projects related to cultural heritage digital preservation. These projects are mostly EU funded.

\section{D-COFORM Project (2008-12-01 to 2012-11-30).}

This project aim is to establish a tool for the digitisation of cultural heritage artefact to bring more realistic representations, better documentation and higher cost-effectiveness of digitisation.

The 3D-COFORM project addresses all aspects of 3D-capture, 3D-processing, semantics of shape, material properties, metadata and provenance, integration with other sources (textual and other media), search, research and dissemination to the public and professional alike.

3D-COFORM also studies the business aspect for the exploitation of 3D aspects and the socio-economic impact [30].

\section{D VIVANT Project (2010-03-01 to 2013-05-31).}

3D VIVANT global aim is to develop a tool that captures video using a novel 3D video technology. This technology is based on 3D Holoscopic imaging. For playback, the project uses holography to provide immersive and ultra-high resolution presentation of 3D content. Various 3D Holoscopic video processing algorithms, such as 3D codecs 
and 3D object segmentation, as well as search and retrieval techniques are developed to optimize broadcasting and search [49].

\section{VENTURI Project (2011-10-01 to 2014-09-30).}

VENTURI is an ambitious initiative which aims at developing and creating a pervasive Augmented Reality (AR) paradigm for mobile devices using advanced 3D technologies and adapted content management framework, where available information will be presented in a 'user' rather than a 'device' centric way. VENTURI goal is also to maintain and optimize current and future mobile platforms adapting its content type and performance settings to each platform to ensure continuity and enrich use cases [50].

V-Must Virtual Transnational museum network (1-02-2011 to 31-01-2015).

V-MusT is an EU-FP7 funded project aiming to provide software tools and best practices to the heritage sector, to promote and develop virtual museums for preservation, education and entertainment purposes. The project investigates also the cohesion that exists in research and aims at reorienting the current research topics [33].

ArchéObjets 3D Project (2015-2016).

The ‘ArchéObjets 3D' Project is funded by Lyon University's PALSE IPEm. This project aims to develop a new 3D scanning technology for hand-held 3D devices like smartphones and tablets. The acquired data is then processed and used in the cultural heritage preservation context. The project main interest is to explore different aspects of 3D rendering and apply them to the various cultural heritage asset types [51].

\section{PRESIOUS Project (2013-02-01 to 2016-01-31).}

PRESIOUS project [52] aim is to investigate and propose new solutions for the difficulty and inefficiency of the 3D digitisation process of cultural heritage assets, the quantification of stone (statues) monument degradation, and the reconstruction of objects from large numbers of constituent fragments. Using a common core of geometric processing, analysis and retrieval methods, PRESIOUS developed predictive geometric augmentation technologies targeted to the above problems [52].

DURAARK Project (2013-02-01 to 2016-01-31).

DURAARK project aim is to develop a new digital preservation framework for architectural data (especially preserving 3D data). This new approach will enhance and redefine access mechanisms, which are generally based on metadata schemes. The new approach will not only focus on the retrieval, but also on fully exploiting the data by different semantic levels. DURAARK will also focus on the future-proof of the preserved data [48]. 
PREFORMA Project (2014-01-01 to 2017-12-31).

PREFORMA [53] aim is to study and implement a better quality standardised file format for cultural information content preservation. It also focuses on formalizing a conformity process for the preservation input (tests and checks).

PREFORMA intended to adapt known archival processes like the OAIS model, specify the critical factors and establish the quality standards that the input data must comply with in order to achieve a sustainable long term preservation.

\section{INCEPTION Project (2015-06-01 to 2019-05-31).}

The main objective of INCEPTION [54] is to develop a new 3D modelling technique adapted to cultural heritage with an inclusive approach for time-dynamic reconstruction. INCEPTION focuses on how to preserve the time line of assets. This methodology will result in accessible 3D models for every user group. INCEPTION aims also at creating an open standard Web Semantics for Building Information models (BIM) adapted to cultural heritage.

\section{LOng Term Archiving and Retrieval - LOTAR PROJECT.}

The main aim of the LOTAR Project [45] is to design, and maintain standards for long term archiving, preservation, and retrieval of data models, especially 3D CAD models and PDM data. The project is conducted by a consortium of aviation and aerospace OEMs and suppliers. LOTAR approach follows the OAIS models and adapts it to the requirement of the aerospace industry.

\section{CEPROQHA Project}

The State of Qatar is a good example of a fast-growing country with a great and long history. Preserving nation's culture is a key challenge in Qatar National vision 2030 and the Qatar National Development Strategy (2011-2016).

Qatar is also leading a new "Smart Nation" initiative whereby the goal is to create a smart, modern, and future proof country. One of the key tasks to achieve this goal is the digital preservation of Qatar's cultural assets.

CEPROQHA $^{1}$ is a cooperative research project between Qatar University and Brunel University (UK), funded by the Qatar National Research Fund (QNRF) under the National Priorities Research Program(NPRP). The project goal is to study how to digitally preserve Qatar's Cultural Heritage. CEPROQHA aims also at developing a bespoke 3D Holoscopic imaging framework that will bring a novel and cost-effective approach to the acquisition, reconstruction, curation, content management, and long-term preservation of cultural heritage assets.

CEPROQHA is aiming to make innovations in:

1 Cost-Effective High-Quality Preservation and Restoration of Qatar Cultural Heritage through Advanced Holoscopic 3D Imaging 
- $\quad$ Cost-effective acquisition and 3D modelling: The majority of 3D scanning approaches lacks efficiency (photogrammetry) or cost-effectiveness (Laser scanning). CEPROQHA will use innovative technologies like 3D Holoscopic imaging and advanced digital curation processes to achieve efficient and cost-effective 3D acquisition and modelling.

- Interoperability and representation of 3D cultural heritage assets: The resulting 3D models must be available in a format that can be rendered for any content consuming platform such as different display types or different representation formats like virtual walk-through. Future 3D visualisation techniques are required following the fast development in the media industry. Hence, interactive visualisation of static 3D objects as well as dynamic visual experience by virtual walk-through is required. - $\quad$ Enrichment, content management and long term preservation: All digitised assets must be linked, annotated and semantically enriched. The content management shall support user annotation, search and retrieval capabilities as well as tools for user-specific data processing and visualisation. Data management should preferably be performed using cloud-based services and storage capabilities. Digital preservation will be deeply studied. CEPROQHA will establish standards and best practices for digital preservation in cultural heritage environment. The overall architecture must comply with established standards to achieve sustainable long term digital preservation.

The CEPROQHA project will benefit from its partners experience in research and innovation in the 3D imaging field. In addition, the project aims at applying available technology to the context of cultural heritage with the perspective of making innovations in 3D acquisition and modelling, 3D content management and annotation and digital long-term preservation.

Overall, CEPROQHA aims are:

- Develop a new evolutionary 3D Holoscopic acquisition approach.

- Develop a new enrichment, processing and reformatting plug-ins for 3D models.

- Develop a bespoke content management system for 3D cultural heritage assets.

- Develop a new and innovative preservation process adapted to cultural heritage assets

\section{Conclusion}

In this paper, we highlighted the advances and most important achievement in the cultural heritage digital preservation field. Cultural heritage artifacts can be treated as products. Their history is a lifecycle that has to be preserved. The high value of $\mathrm{CH}$ assets and their specificities require the development of a bespoke preservation framework. Our study covered these basic requirements, starting from 3D acquisition and enrichment, followed by $\mathrm{CH}$ content management, and finally, the long-term digital preservation. We also surveyed some projects related to $\mathrm{CH}$ acquisition, curation, management, and preservation. 
At the end of this document, we presented the CEPROQHA project which our team is part of. CEPROQHA in an innovative approach toward $\mathrm{CH}$ digital management and preservation. The CEPROQHA team is really committed to make an innovative proof of concept for 3D digital preservation of the Qatari cultural heritage using cutting edge 3D imaging technologies.

\section{Acknowledgement}

This publication was made possible by NPRP grant 9-181-1-036 from the Qatar National Research Fund (a member of Qatar Foundation). The statements made herein are solely the responsibility of the authors.

\section{$7 \quad$ References}

1. Santos, P. Ritz, M.: CultLab3D - Fast and Economic, High Quality 3D Digitization of Cultural Heritage Artifacts. Dieter Fritsch (Ed.) Photogrammetric Week 13, 319-322 (2013)

2. Deljanin, Sandra. Digital Obsolescence. INFOtheca-Journal of Informatics \& Librarianship 13.1, 43-53 (2012)

3. Barbau, R.: A reference architecture for archival systems with application to product models, https://tel.archives-ouvertes.fr/tel-00924492, (2013)

4. Barbau, R., Krima, S., Rachuri, S., Narayanan, A., Fiorentini, X., Foufou, S., Sriram, R.D.: OntoSTEP: Enriching product model data using ontologies. Comput.-Aided Des. 44, 575590 (2012). doi: 10.1016/j.cad.2012.01.008

5. Barbau, R., Lubell, J., Rachuri, S., Foufou, S.: Toward a Reference Architecture for Archival Systems. In: Bernard, A., Rivest, L., and Dutta, D. (eds.) Product Lifecycle Management for Society: 10th IFIP WG 5.1 International Conference, PLM 2013, Nantes, France, July 6-10, 2013, Proceedings. pp. 68-77. Springer Berlin Heidelberg, Berlin, Heidelberg (2013). doi:10.1007/978-3-642-41501-2_8

6. Wilkes, W., Brunsmann, J., Heutelbeck, D., Hundsdörfer, A., Hemmje, M., Heidbrink, H.: Towards Support for Long-Term Digital Preservation in Product Life Cycle Management. International Journal of Digital Curation. 6, 282-296 (2011). doi:10.2218/ijdc.v6i1.188

7. Lee, S.: Standardization of Digital Archiving and OAIS Reference Model. Journal of Information Management. 33, 45-68 (2002). doi: 10.1633/JIM.2002.33.3.045

8. Scopigno, R., Callieri, M., Cignoni, P., Corsini, M., Dellepiane, M., Ponchio, F., Ranzuglia, G.: 3D Models for Cultural Heritage: Beyond Plain Visualization. Computer. 44, 48-55 (2011). doi:10.1109/MC.2011.196

9. Pavlidis, G., Koutsoudis, A., Arnaoutoglou, F., Tsioukas, V., Chamzas, C.: Methods for 3D digitization of Cultural Heritage. Journal of Cultural Heritage. 8, 93-98 (2007). doi: 10.1016/j.culher.2006.10.007

10. Selva3D - Transform images into 3D models online, https://www.selva3d.com

11. Smoothie-3D. http://www.smoothie-3d.com

12. Autodesk 123D. http://www.123dapp.com

13. Brutto, M.Meli, P.: Computer Vision Tools for 3D Modelling in Archaeology. International Journal of Heritage in the Digital Era. 1, 1-6 (2012). doi: 10.1260/2047-4970.1.0.1

14. Google Tango. https://get.google.com/tango

15. AgiSoft, L. L. C. Agisoft photoscan. Professional Edition (2014) 
16. Pix4D. https://pix4d.com

17. ARC 3D Web Service. http://www.arc3d.be

18. PhotoModeler. http://www.photomodeler.com

19. Singh, G.: CultLab3D: Digitizing Cultural Heritage. IEEE Computer Graphics and Applications. 34, 4-5 (2014). doi:10.1109/MCG.2014.48

20. Levoy, M.: The Digital Michelangelo Project. Computer Graphics Forum. 18, xiii-xvi (1999)

21. Sansoni, G., Trebeschi, M., Docchio, F.: State-of-The-Art and Applications of 3D Imaging Sensors in Industry, Cultural Heritage, Medicine, and Criminal Investigation. Sensors. 9, 568-601 (2009). doi:10.3390/s90100568

22. Pieraccini, M., Guidi, G., Atzeni, C.: 3D digitizing of cultural heritage. Journal of Cultural Heritage. 2, 63-70 (2001). doi:10.1016/S1296-2074(01)01108-6

23. Alsadik, B., Gerke, M., Vosselman, G.: Automated camera network design for 3D modeling of cultural heritage objects. Journal of Cultural Heritage. 14, 515-526 (2013). doi: 10.1016/j.culher.2012.11.007

24. MeshLab. http://www.meshlab.net

25. Swash, M., Aggoun, A., Abdulfatah, O., Li, B., Fernandez, J., Tsekleves, E.: Holoscopic 3D image rendering for Autostereoscopic Multiview 3D Display. 2013 IEEE International Symposium on Broadband Multimedia Systems and Broadcasting (BMSB). (2013). doi:10.1109/BMSB.2013.6621683

26. Aggoun, A., Tsekleves, E., Swash, M., Zarpalas, D., Dimou, A., Daras, P., Nunes, P., Soares, L.: Immersive 3D Holoscopic Video System. IEEE MultiMedia. 20, 28-37 (2013). doi: 10.1109/MMUL.2012.42

27. Aggoun, A.: 3D Holoscopic Imaging Technology for Real-Time Volume Processing and Display. Signals and Communication Technology. 411-428 (2010). doi:10.1007/978-3-64212802-8_18

28. CIDOC-CRM, CRMdig. http://doc.objectspace.org/cidoc

29. Falcidieno, B.: Special session AIM@SHAPE project presentation. Proceedings Shape Modeling Applications, 2004. doi:10.1109/SMI.2004.1314520

30. Pitzalis, D., Kaminski, J., Niccolucci, F.: 3D-COFORM: Making 3D documentation an everyday choice for the cultural heritage sector. Virtual Archaeology Review. 2, 145 (2011). doi:10.4995/var.2011.4571

31. Catalano, C. FOCUS K3D Road map for future research. Technical report. http://www.focusk3d.eu

32. CULTURA (Cultivating Understanding and Research through Adaptivity). http://www.cultura-strep.eu

33. v-must | Virtual Museum Transnational Network. http://v-must.net

34. Collection Management Software for Museums. http://www.zetcom.com

35. Santos, P., Serna, S.P., Stork, A., Fellner, D.: The Potential of 3D internet in the cultural heritage domain. In: Ioannides, M., Quak, E. (eds.) 3D Research Challenges. LNCS, vol. 8355, pp. 1-17. Springer, Heidelberg (2014) doi: 10.1007/978-3-662-44630-0_1

36. Llamas, J., Lerones, P., Zalama, E., Gómez-García-Bermejo, J.: Applying Deep Learning Techniques to Cultural Heritage Images Within the INCEPTION Project. Digital Heritage. Progress in Cultural Heritage: Documentation, Preservation, and Protection. 25-32 (2016).

37. PastPerfect: The World's Leading Museum Collection Software, http://www.museumsoftware.com

38. Adlib - Flexible Software for Archives, Museums and Libraries. http://www.adlibsoft.com 
39. Pan, X., Schiffer, T., Schröttner, M., Berndt, R., Hecher, M., Havemann, S., Fellner, D.: An Enhanced Distributed Repository for Working with 3D Assets in Cultural Heritage. Progress in Cultural Heritage Preservation. 349-358 (2012). doi: 10.1007/978-3-642-34234-9_35

40. Versoteq. http://versoteq.com

41. 3D STELLWERK, http://3dstellwerk.com

42. Sketchfab. http://sketchfab.com

43. Felicetti, A.Lorenzini, M.: Metadata and Tools for Integration and Preservation of Cultural Heritage 3D Information. Geoinformatics FCE CTU. 6, 118-124 (2011). doi: 10.14311/gi.6.16

44. Doyle, J., Viktor, H., Paquet, E.: Preservation metadata - a framework for 3D data based on the Semantic Web. 2008 Third International Conference on Digital Information Management. (2008). doi:10.1109/ICDIM.2008.4746811

45. LOng Term Archiving and Retrieval, http://www.lotar-international.org

46. MacKenzie, S.: Future-Proofing Architectural Computer-Aided Design: MIT's FACADE Project. In: Peyceré, D. Wierre, F. Koch,C. Architecture et archives numériques - L'architecture à l'ère numérique : un enjeu de mémoire, édition bilingue français-anglais, pp. 408423. Editions InFolio (2008)

47. DEDICATE Project. http://gtr.rcuk.ac.uk/projects?ref=AH\%2FJ008265\%2F1

48. DuraArk project. http://duraark.eu

49. Steurer, J., Pesch, M., Hahne, C.: 3D holoscopic video imaging system. Human Vision and Electronic Imaging XVII. (2012). doi:10.1117/12.915294

50. Venturi Project. https://venturi.fbk.eu

51. Arché3DObjet Project blog. http://archeorient.hypotheses.org/6692

52. PRESSIOUS Project Website. http://www.presious.eu

53. PREFORMA Project Website. http://www.preforma-project.eu

54. INCEPTION Project Website. http://www.inception-project.eu 